Reprod. Nutr. Dévelop., 1986, 26 (1 B), 377-378.

\title{
Evolution du taux plasmatique de CCK avec l'âge et le régime alimentaire chez le jeune veau
}

\author{
P. GUILLOTEAU, J. A. CHAYVIALLE (*), R. TOULLEC, J. F. GRONGNET, C. DARDIL- \\ LAT $\left({ }^{* *}\right)$, Christine BERNARD $\left(^{*}\right)$
}

Laboratoire du Jeune Ruminant, I.N.R.A., 65 rue de Saint-Brieuc, 35042 Rennes Cédex. (*) Unité de Recherches de Physiopathologie Digestive, I.N.S.E.R.M., 69374 Lyon Cédex.

(*) Laboratoire de la Digestion, I.N.R.A., Theix 63122 Ceyrat.

Summary. Newborn calves given colostrum showed an increase of plasma immunoreactive cholecystokinin (CCK). Thereafter, in preruminant animals, CCK level was higher $1 \mathrm{~h}$ after the morning meal than before feeding, especially when milk protein was replaced by fish protein. The postprandial increase was not observed after weaning.

Nous avons mesuré les variations du taux plasmatique de cholécystokinine immunoréactive $(C C K)$ à la naissance, pendant le maintien prolongé au stade préruminant et au cours du sevrage.

L'adaptation à la vie aérienne et l'effet des premiers repas sont étudiés chez 11 veaux nouveau-nés Holstein $x$ Frison qui sont soit nourris $(25 \mathrm{~g}$ de colostrum.kg $\left.P V^{-1}\right)$ à 4, 10, 16, 22 et $28 \mathrm{~h}(\mathrm{~N}, \mathrm{n}=5)$, soit maintenus à jeun jusqu'à $28 \mathrm{~h}(\mathrm{~J}, \mathrm{n}=6)$. Des échantillons de sang jugulaire sont prélevés sur héparine et aprotinine dans la minute qui suit la naissance, quelques minutes avant et $1 \mathrm{~h}$ après chaque repas, ainsi qu'au bout de $30 \mathrm{~h}$ chez les veaux $\mathrm{N}$ et en même temps chez les animaux J. Le taux plasmatique de CCK est mesuré par radioimmunologie (Miazza et al., 1985). Le taux observé à la naissance est de $25 \mathrm{pg} . \mathrm{ml}^{-1}$. II augmente ensuite fortement chez les veaux $N$, surtout après chaque repas, jusqu'à $170 \mathrm{pg} \cdot \mathrm{ml}^{-1}$ à $29 \mathrm{~h}$ (fig. 1A). Chez les veaux J, le taux reste inférieur à $27 \mathrm{pg} . \mathrm{ml}^{-1}$ de 0 à $28 \mathrm{~h}$; il double après le premier repas mais il reste encore 3 fois plus faible que chez les veaux $N$.

Pour déterminer l'effet de l'âge et du repas pendant le stade préruminant, 5 des 11 veaux précédents reçoivent entre les âges de 2 et 91 jours, un lait de remplacement ( $25 \mathrm{~g}$ de protéines et $20 \mathrm{~g}$ de lipides. $100 \mathrm{~g}$ de $\mathrm{MS}^{-1}$ ) dont les protéines sont apportées par de la poudre de lait écrémé. Les animaux sont nourris 2 fois par jour $(8 \mathrm{~h} 30$ et $16 \mathrm{~h} 30$ ) et la quantité reçue augmente progressivement de 600 à $2500 \mathrm{~g} \mathrm{MS}^{-1}{ }^{-1}$. Les échantillons de sang jugulaire sont prélevés avant et $1 \mathrm{~h}$ après le repas du matin, chaque jour pendant la première semaine puis une fois par semaine. Le taux de CCK à jeun passe de moins de $50 \mathrm{pg} \cdot \mathrm{ml}^{-1}$ à environ 80 en 20 jours (fig. 1B). Comme chez le nouveau-né, le taux est toujours plus élevé après le repas qu'à jeun (en moyenne 1,5 fois).

Pour étudier l'effet de la source de protéines, 3 veaux reçoivent, entre les âges de 6 et 9 semaines, 2 laits de remplacement $(25 \mathrm{~g}$ de protéines et $20 \mathrm{~g}$ de lipides. $100 \mathrm{~g}$ de $\mathrm{MS}^{-1}$ ) dont les protéines sont apportées par de la poudre de lait écrémé ou un concentrat de poissons blancs partiellement hydrolysé (CPSP 90, CTPP, 62203 Boulogne-sur-Mer) et de la poudre de lactosérum (respectivement 74 et $26 \%$ ). Chaque aliment est distribué pendant au moins 10 jours avant le début des prises de sang. Celles-ci ont lieu depuis $2 \mathrm{~h}$ avant le repas du matin jusqu'à $8 \mathrm{~h}$ après, à raison de $8 \mathrm{j}$ avec chaque régime. Avec l'aliment Poisson, l'augmentation postprandiale du taux de CCK est plus précoce (moins de 30 min au lieu de $1 \mathrm{~h} \mathrm{30}$ ) et plus forte (multiplication par 2,2 au lieu de 1,3) ; le taux reste plus élevé pendant les 5 premières heures (fig. 1c) ; cela est probablement à relier à l'évacuation gastrique plus rapide des protéines et des lipides de cet aliment. 
L'effet du sevrage est étudié chez 5 des 11 veaux utilisés à la naissance. Jusqu'à l'âge de 21 jours, ces animaux sont nourris exclusivement avec un lait de remplacement ; ensuite, ils reçoivent ad libitum du foin, un aliment concentré $\left(3 \mathrm{~kg} . \mathrm{j}^{-1}\right)$ et de l'eau, tandis que l'alimentation lactée est progressivement réduite puis supprimée à 56 jours. Le lait de remplacement et les modalités des prises de sang sont les mêmes que dans l'étude de l'effet de l'âge et du repas. Jusqu'à 21 jours, le taux de CCK est plus élevé après le repas qu'avant (fig. 1D) ; la différence diminue pendant le sevrage et disparaît ensuite. Le taux rend à diminuer à partir de 77 jours. Pendant le sevrage et les 21 jours suivants, les valeurs préprandiales sont plus élevées que chez les veaux préruminants de même âge ; en revanche, les valeurs postprandiales sont voisines chez les 2 groupes d'animaux, sauf à 91 jours où elles sont significativement plus faibles chez les veaux sevrés. Cela résulte d'un flux duodénal plus continu dû au développement des préestomacs et au plus grand étalement de la prise alimentaire. Le taux élevé observé avant le repas, surtout à la fin du sevrage et immédiatement après, pourrait être relié au faible appétit des animaux durant cette période (Della-Ferra et Baile, 1979).
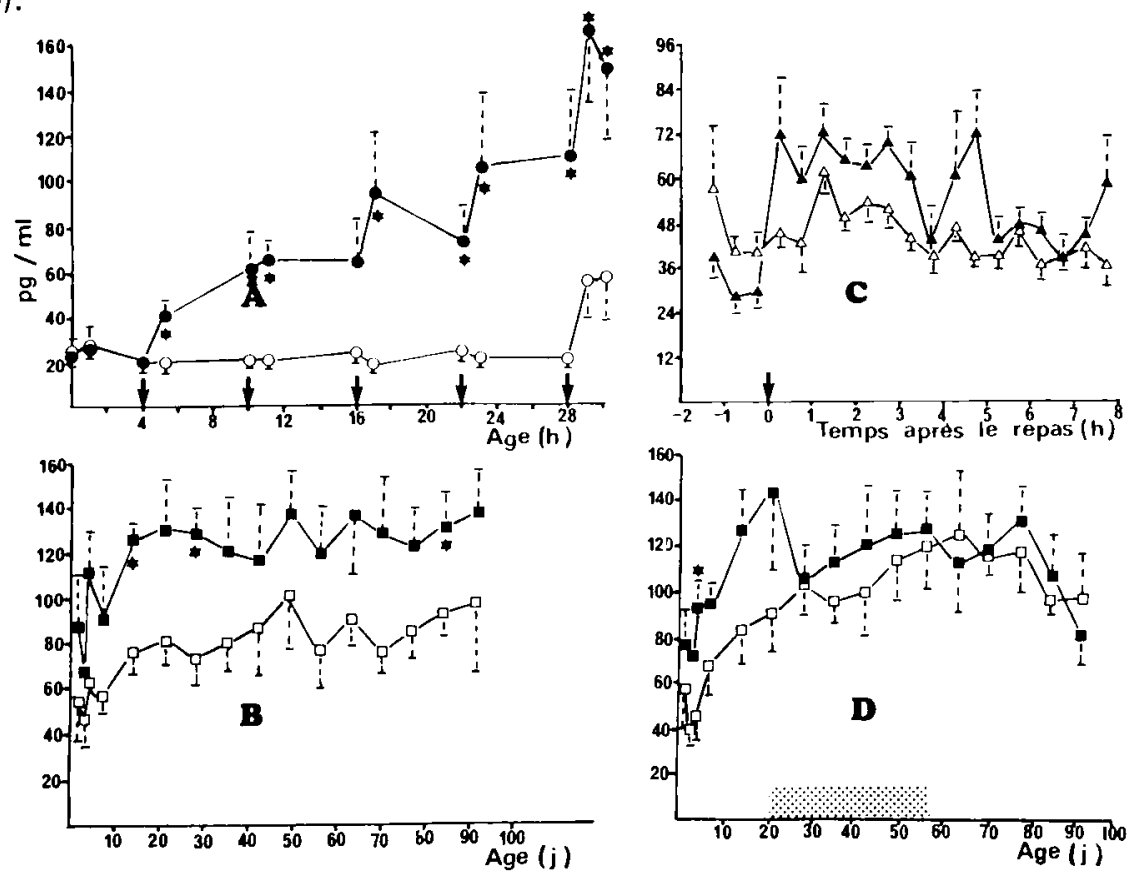

FIG. 1. - Evolution du taux plasmatique de CCK chez le veau (moyennes et écarts-types des moyennes) : effets des premiers repas chez le nouveau-né (A), de l'âge $(B)$ et de la source de protéine $(\mathrm{C})$ chez le préruminant et du sevrage (D) ; ! : repas ; zone ombrée : période de sevrage ; ${ }^{*}$ : valeurs significativement différentes à la même heure ( $A$ et $C$ ) ou au même jour ( $B$ et $D$ ). $D:$ veaux maintenus à jeun pendant les 28 premières heures postnatales ; $:$ veaux nourris $4,10,16,22$ et 28 h après la naissance ; avant $(\square)$ et $1 \mathrm{~h}$ après $(\square)$ la distribution du repas du matin ; aliments Lait $(\triangle)$ et Poisson (A).

Della-Ferra M. A., Baille C. A., 1979. CCK octapeptide injected in CSF causes satiety in sheep. Ann. Rech. vét., 10, 234-236.

Miazza B., Palma R., Lachance J. R., Chayvialle J. A., Jaunard P., Modigliani R., 1985. Jejunal secretory effect of intraduodenal food in humans : a comparison of mixed nutrients, proteins, lipids and carbohydrates. Gastroenterology, 88, 1215-1222. 